\title{
Forum
}

\section{Tilting at wildlife: reconsidering human-wildlife conflict}

\author{
Stephen Mark Redpath, Saloni Bhatia and Juliette Young
}

\begin{abstract}
Conflicts between people over wildlife are widespread and damaging to both the wildlife and people involved. Such issues are often termed human-wildlife conflicts. We argue that this term is misleading and may exacerbate the problems and hinder resolution. A review of 100 recent articles on human-wildlife conflicts reveals that 97 were between conservation and other human activities, particularly those associated with livelihoods. We suggest that we should distinguish between human-wildlife impacts and human-human conflicts and be explicit about the different interests involved in conflict. Those representing conservation interests should not only seek technical solutions to deal with the impacts but also consider their role and objectives, and focus on strategies likely to deliver long-term solutions for the benefit of biodiversity and the people involved.
\end{abstract}

Keywords Conflict resolution, human-human conflict, human-wildlife conflict, human-wildlife impact

\section{Introduction}

Tn a famous scene from Cervantes' (1605) novel Don 1 Quixote, the eponymous hero perceives a phalanx of windmills rising from the Spanish plains as 'hulking giants', and he charges on his horse, intending to slay them. Needless to say, this doesn't go well. Moreover, Quixote's inability to appropriately identify his adversaries is repeated throughout the book, leading him into all sorts of difficult circumstances.

Just as Don Quixote misidentified his foe, we consider whether we misidentify the antagonists in human-wildlife conflict and thereby limit the likelihood of finding effective solutions. We consider the way human-wildlife conflict is defined and briefly explore the literature to examine who these conflicts are between. We ask whether the term is appropriate or whether it reduces our ability to find solutions

\footnotetext{
StePHen MARK ReDPath (Corresponding author) Institute of Biological and Environmental Sciences, University of Aberdeen, Zoology Building, Tillydrone Avenue, Aberdeen, AB2 42TZ, UK. E-mail s.redpath@abdn.ac.uk

SALONI BHATIA Nature Conservation Foundation, Mysore, Karnataka, India Juliette Young Centre for Ecology \& Hydrology, Penicuik, Midlothian, UK

Received 16 June 2014. Revision requested 18 July 2014.

Accepted 29 August 2014. First published online 11 November 2014.
}

to the problem of coexistence with challenging species. These issues are of high relevance for policy in view of the fact that increasing pressure on natural systems is likely to increase the importance and magnitude of such conflicts, with negative repercussions for biodiversity and human livelihoods and well-being (Young et al., 2010).

\section{Defining human-wildlife conflicts}

The term conflict is defined variously in the Oxford Concise Dictionary as 'a state of opposition or hostilities', 'a fight or a struggle' and 'a clashing of opposed principles'. The term therefore suggests action between two or more antagonists. Conflict is integral to conservation; those who defend conservation objectives often find themselves in conflict with those with other interests and objectives. Human-wildlife conflict in particular is widespread and has been the subject of a large number of publications. Conover (2002) defined these interactions as 'situations occurring when an action by either humans or wildlife has an adverse effect on the other'. This framing implies that species are in conflict with people, such as in the case of elephant-human conflicts (e.g. Wilson et al., 2013). In more extreme cases, we also see orang-utan-palm oil conflicts (Nantha \& Tisdell, 2009) and protected area-community conflicts (Liu et al., 2010).

This widely used framing of human-wildlife conflict has been criticized. Peterson et al. (2010) pointed out that the portrayal of animals as 'conscious human antagonists' and 'combatants against people' is problematic as it masks the underlying human dimension (see also Marshall et al., 2007; Raik et al., 2008; White et al., 2009; Young et al., 2010). Orang-utans Pongo pygmaeus and oil palm Elaeis guineensis are not in conflict with each other. Instead, these conflicts are between those who want to protect the orang-utan and those wanting to promote oil palm plantations. Of course, oil palm plantations may have damaging impacts on these great apes but the conflict is between the conservationists and developers. This confusion led Young et al. (2010) to suggest that human-wildlife conflicts should be split into their two components: human-wildlife impacts, which focus on the impacts of wildlife on humans and their activities, and the underlying human-human conflicts between those defending pro-wildlife positions and those defending other positions. An alternative definition of conflicts over biodiversity has therefore been proposed 
as: situations that arise when two or more parties have strongly held views [over biodiversity objectives] and one of those parties is attempting to assert its interests at the expense of the other (Bennett et al., 2001; Marshall et al., 2007; White et al., 2009; Young et al., 2010; Redpath et al., 2013). Yet, despite these concerns and suggestions, it is clear that the way in which these issues are framed remains broadly unchanged.

\section{Human-wildlife conflict literature}

It is undoubtedly the case that many conflicts arise when humans and wildlife interact, especially when the wildlife in question is a large charismatic species (Peterson et al., 2010). In April 2013 we used ISI Web of Knowledge to locate 100 case studies, published since 2010, on human-wildlife conflict, aiming for a broad overview of the subject. We searched for articles containing the phrases 'human-wildlife conflict' or 'human-animal conflict' (we did not to do a systematic review of the available literature). The databases included in the search were Science Citation Index-Expanded, Social Sciences Citation Index, Arts and Humanities Citation Index, Conference Proceedings Citation IndexScience, Conference Proceedings Citation Index-Social Science \& Humanities. For multiple articles on the same study system we took the most recent one. We excluded reviews and discussion articles.

For each case study, SB identified whether the species in question was of conservation interest (i.e. on the IUCN Red List; IUCN, 2014) and the broad objectives underlying either side of the conflict, which were categorized based on the abstract and title (Table 1). Although the articles were primarily coded by SB, the typology was developed by all three authors, and in rare cases of uncertainty the article was coded by mutual agreement.

Of the 100 articles, 97 involved species of conservation interest. Most of the species involved were predators $(54 \%)$ or large herbivores $(42 \%)$. We identified the underlying conflicts as primarily being between conservation objectives and either livelihood (65\%) or human safety and health objectives (15\%). Others involved conservation and recreation (8\%), development and infrastructure (4\%), animal welfare $(3 \%)$ and human well-being $(2 \%)$. In other words, almost all human-wildlife conflicts were between those who sought to defend conservation objectives and those defending other, mainly livelihood, objectives.

\section{Does language matter?}

Does it really matter if we continue to frame these issues as human-wildlife conflicts? Peterson et al. (2010) argued that it does because it perpetuates the problem and reduces options for solutions. Using the human-wildlife conflict frame
TABLE 1 Descriptions of competing objectives identified in articles on human-wildlife conflict.

\begin{tabular}{ll}
\hline Objective & Description \\
\hline Conservation & $\begin{array}{l}\text { Emphasis on the need to defend conser- } \\
\text { vation objectives; e.g. protecting threat- } \\
\text { ened species on the IUCN Red List or } \\
\text { upholding conservation legislation } \\
\text { Emphasis on livelihood impact of the } \\
\text { conflict; e.g. impact on farming, fishing } \\
\text { Livelihood }\end{array}$ \\
$\begin{array}{l}\text { Emphasis on ethics \& moral responsibility } \\
\text { towards the species in conflict, especially } \\
\text { in human-dominated landscapes; e.g. } \\
\text { urban wildlife management }\end{array}$ \\
$\begin{array}{l}\text { Emphasis on public health \& safety con- } \\
\text { cerns arising out of conflict }\end{array}$ \\
$\begin{array}{l}\text { Emphasis on recreation; e.g. tourism or } \\
\text { trophy hunting }\end{array}$ \\
Recreation & $\begin{array}{l}\text { Emphasis on the impact of infrastructure } \\
\text { activities (e.g. road construction) on con- } \\
\text { servation of the species in conflict } \\
\text { Emphasis on psychological or spiritual } \\
\text { infrastructure }\end{array}$ \\
Human well-being & $\begin{array}{l}\text { well-being of people, including percep- } \\
\text { tions of risk, or spiritual/religious con- } \\
\text { nection of people with the species }\end{array}$ \\
\hline
\end{tabular}

may label nature as threatening, leading to misunderstanding and ultimately negative consequences for nature (McComas, 2006). This is similar to the problem identified in studies of invasive species, where it has been argued that militaristic metaphors are problematic because they give an inaccurate perception of the species involved and contribute to misunderstanding (Larson, 2005). We also know that the way problems are framed has repercussions. For example, the way that the news is framed by the media is believed to influence the political agenda as well as prime readers to think in a certain way (McCombs \& Shaw, 1972; Scheufele, 1999). So we may hypothesize that presenting wildlife as antagonistic may alter the way people perceive those species.

Furthermore, if we continue to view these conflicts as being between humans and wildlife then the approach taken to tackle conflicts will be focused on technical solutions rather than on the underlying conflict. Technical solutions aimed at reducing the impact of wildlife on humans may be successful (e.g. Woodroffe et al., 2005). For example, technical solutions such as tripwires or community-based guarding or chilli deterrents to minimize damage from elephants may be successful (Hedges \& Gunaryadi, 2010). However, because conflicts are fundamentally between people, technical solutions are unlikely to focus on the underlying problem unless both parties support their use. So just because a particular technical solution may be effective at reducing impacts does not mean that conflicts between conservation and livelihood objectives are addressed. 


\section{A way forward?}

Peterson et al. (2010) suggested, like Madden (2004) before them, that instead of using the term human-wildlife conflict we should use human-wildlife coexistence as a more constructive way of framing the issue. However, we contend that we need to do more than this. We need to be explicit about the underlying human-human dimension. Transparency about the nature of these conflicts is needed before we can identify effective means of dealing with them (Linnell et al., 2010; Young et al., 2013). This partly involves distinguishing between human-wildlife impacts and human-human conflicts (Young et al., 2010). It also means being unambiguous about the specific interests involved. In the majority of cases human-wildlife conflicts are between conservation and other human interests. In these cases, we suggest that it may be more productive to stop hiding behind the wildlife and be clear that those who are defending the conservation objectives are the antagonists.

This distinction is important because the focus will inevitably move from a focus on impact and technical solutions to consideration of how to negotiate solutions between these competing interests. Although technical approaches are likely to be an important part of the solution, we suggest that the main thrust should be a policy context that encourages dialogue between the interest groups to understand goals, explore the evidence and negotiate ways forward (Redpath et al., 2013).

We illustrate these points with an example one of us (SR) has worked on. In the UK, hen harriers Circus cyaneus have an impact on red grouse Lagopus lagopus scoticus populations, and there is a conflict between those interested in harrier conservation and those interested in grouse shooting (Thirgood \& Redpath, 2008). At the outset this was typically considered as a human-wildlife conflict and a number of technical solutions were proposed (Thirgood et al., 2000). One technical solution that was subsequently tested and found to be highly effective in reducing impact was the use of diversionary feeding (Redpath et al., 2001). Yet, despite its effectiveness, the solution has not been taken up by grouse managers, and the conflict continues because the technique was aimed at reducing impact rather than addressing the underlying conflict (Thirgood \& Redpath, 2008). We suggest that should a shared solution be sought, then a more productive approach will be to address the underlying conflict by building trust and understanding between the groups. Being explicit about the human antagonists will help open up the space and expertise to search for sustainable solutions.

\section{The role of conservation}

This reframing of many human-wildlife conflicts as being between conservation and other human activities highlights another potential problem. Given the urgency that is integral to conservation, it is unsurprising that in many cases conservation biologists are dealing with the conflict. It may be problematic to have a party who is an antagonist in the conflict leading the search for solutions as this party will not be an independent arbiter in the conflict. Conservation biologists may focus on top-down approaches, such as enforcing legislation on unwilling stakeholders or tokenistic participatory approaches in which false expectations are raised within a legislative context that cannot be changed. In addition, conservation biologists are naturally going to focus on delivering conservation outcomes, such as an increase in species number, rather than striving for outcomes that seek to benefit both parties. The concern here is that this biased focus may exacerbate the conflict, by antagonizing the other party, rather than resolving it. Care is required when thinking about what role individuals and organizations should play in these issues, what outcomes are sought by those involved, what processes will enable negotiation of alternative solutions, and from a conservation perspective which approach will lead to more effective long-term conservation outcomes (Redpath et al., 2013).

\section{Discussion}

Within this field of conservation conflicts, we suggest that in many cases researchers, planners and practitioners are still attempting, like Don Quixote, to slay falsely identified conflicts, with the consequent difficulties. There is a need to consider carefully the way we use the term human-wildlife conflict and to clearly distinguish between human-wildlife impacts and the underlying human-human conflicts between conservation and other human interests. These distinctions are important as they highlight that many of the underlying arguments are between conservation and other human activities over how to manage a large predator or herbivore, rather than between humans and the species involved, where the species act as a surrogate for conservation interests.

To date, human-wildlife conflicts have proven challenging to manage, in part, we contend, because in the majority of cases they are researched by conservation biologists working to understand and mitigate ecological impact rather than the social dimensions (Knight et al., 2006). We suspect that it will be more productive to tackle the underlying human dimensions by working with affected communities (Gregory, 2000; Knight et al., 2006) and with those skilled in negotiation, to openly and transparently explore the options with conservation biologists, recognizing they are only one of the parties involved in that negotiation (e.g. Biggs et al., 2011). This will require the role of conservation in these conflicts to be acknowledged explicitly, the goals to 
be articulated and some will to negotiate solutions within the existing legal and political context. Although policymakers and conservation biologists are increasingly recognizing the need for such an approach in conservation generally, these issues are pressing within conflict situations where there is an urgent need to tackle effectively and sustainably the serious problems that threaten the conservation of biodiversity and other human activities.

\section{References}

Bennett, E., Neiland, A., Anang, E., Bannerman, P., Rahman, A. A., HuQ, S. et al. (2001) Towards a better understanding of conflict management in tropical fisheries: evidence from Ghana, Bangladesh and the Caribbean. Marine Policy, 25, 365-376.

Biggs, D., Abel, N., Knight, A.T., Leitch, A., Langston, A. \& BAN, N.C. (2011) The implementation crisis in conservation planning: could "mental models" help? Conservation Letters, 4, 169183.

Cervantes, Miguel de (1605) Don Quixote. Translated by Edith Grossman. Harper Collins, New York, USA (2003).

Conover, M.R. (2002) Resolving Human-Wildlife Conflicts: The Science of Wildlife Damage Management. CRC Press, Boca Raton, USA.

GREGORY, R. (200o) Using stakeholder values to make smarter environmental decisions. Environment, 42, 34-44.

Hedges, S. \& Gunaryadi, D. (2010) Reducing human-elephant conflict: do chillies help deter elephants from entering crop fields? Oryx, 44, 139-146.

IUCN (2014) IUCN Red List of Threatened Species v. 2014.2. Http:// www.iucnredlist.org [accessed July 2014].

Knight, A.T., Cowling, R.M. \& Campbell, B.M. (2006) An operational model for implementing conservation action. Conservation Biology, 20, 408-419.

LARSON, B.M.H. (2005) The war of the roses: demilitarizing invasion biology. Frontiers in Ecology and the Environment, 3, 495-500.

Linnell, J.D.C., Rondeau, D., Reed, D.H., Williams, R., AltwegG, R., Raxworthy, C.J. et al. (2010) Confronting the costs and conflicts associated with biodiversity. Animal Conservation, 13, 429-431.

Liu, J., Ouyang, Z. \& Miao, H. (2010) Environmental attitudes of stakeholders and their perceptions regarding protected area-community conflicts: a case study in China. Journal of Environmental Management, 91, 2254-2262.

Madden, F. (2004) Creating coexistence between humans and wildlife: global perspectives on local efforts to address humanwildlife conflict. Human Dimensions of Wildlife, 9, 247-257.

Marshall, K., White, R. \& Fischer, A. (2007) Conflicts between humans over wildlife management: on the diversity of stakeholder attitudes and implications for conflict management. Biodiversity Conservation, 16, 3129-3146.

McComas, K.A. (2006) Defining moments in risk communication research: 1996-2005. Journal of Health Communication, 11, 75-91.
MсСомвs, M.E. \& SнAw, D.L. (1972) The agenda-setting function of mass media. Public Opinion Quarterly, 36, 176-187.

Nantha, H.S. \& Tisdell, C. (2009) The orangutan-oil palm conflict: economic constraints and opportunities for conservation. Biodiversity and Conservation, 18, 487-502.

Peterson, M.N., Birckhead, J.L., Leong, K., Peterson, M.J. \& Peterson, T.R. (2010) Rearticulating the myth of human-wildlife conflict. Conservation Letters, 3, 74-82.

Raik, D.B., Wilson, A.L. \& DeCKer, D.J. (2008) Power in natural resources management: an application of theory. Society \& Natural Resources, 21, 729-739.

Redpath, S.M., Thirgood, S.J. \& Leckie, F.M. (2001) Does supplementary feeding reduce predation of red grouse by hen harriers? Journal of Applied Ecology, 38, 1157-1168.

Redpath, S.M., Young, J., Evely, A., Adams, W.M., Sutherland, W.J., Whitehouse, A. et al. (2013) Understanding and managing conservation conflicts. Trends in Ecology \& Evolution, 28, 100-109.

SCheufele, D.A. (1999) Framing as a theory of media effects. Journal of Communication, 49, 103-122.

Thirgood, S. \& Redpath, S. (2008) Hen harriers and red grouse: science, politics and human-wildlife conflict. Journal of Applied Ecology, 45, 1550-1554

Thirgood, S., Redpath, S., Newton, I. \& Hudson, P. (2000) Raptors and red grouse: conservation conflicts and management solutions. Conservation Biology, 14, 95-104.

White, R.M., Fischer, A., Marshall, K., Travis, J.M., Webb, T.J., Di FALCO, S. et al. (2009) Developing an integrated conceptual framework to understand biodiversity conflicts. Land Use Policy, 26, 242-253.

Wilson, S., Davies, T.E., Hazarika, N. \& Zimmermann, A. (2013) Understanding spatial and temporal patterns of human-elephant conflict in Assam, India. Oryx, http://dx.doi.org/10.1017/ Soo30605313000513

Woodroffe, R., Thirgood, S. \& Rabinowitz, A. (eds) (2005) People and Wildlife: Conflict or Co-Existence? Cambridge University Press, Cambridge, UK

Young, J.C., Jordan, A., Searle, K.R., Butler, A., Chapman, D.S., Simmons, P. \& Watт, A.D. (2013) Does stakeholder involvement really benefit biodiversity conservation? Biological Conservation, $158,359-370$.

Young, J.C., Marzano, M., White, R.M., McCracken, D.I., Redpath, S.M., Carss, D.N. et al. (2010) The emergence of biodiversity conflicts from biodiversity impacts: characteristics and management strategies. Biodiversity and Conservation, 19, 39733990.

\section{Biographical sketches}

STEPHEN REDPATH is interested in understanding and managing conflicts in conservation. SALONI BHATIA's research is focused on tolerance in relation to living with carnivores. JU LIE T TE YOUNG studies the political science of conflict. 